\title{
LA NECESARIA RELEVANCIA PARA EL PRECIO DE LOS VALORES DE LA INFORMACIÓN FALSA DEL ART. 59 LETRA A) DE la Ley de Mercado de Valores
}

[The necessary relevance for the securities price of the false information of Art. 59 letter a) of the Securities Market Act]

\section{Héctor Hernández BASUALTO*}

\section{RESUMEN}

El artículo aborda los alcances del tipo penal de entrega de antecedentes falsos del art. 59 letra a) de la Ley de Mercado de Valores, específicamente en lo que concierne al objeto de la falsedad. Se sostiene que sólo la entrega de antecedentes falsos relevantes para el precio de los valores satisface las exigencias típicas, de modo que la entrega de otro tipo de antecedentes, aunque igualmente falsos, en particular de aquéllos requeridos por la Superintendencia de Valores en el ejercicio de su actividad de fiscalización, pero sin potencial para incidir en el precio de los valores, queda fuera del ámbito de aplicación del tipo. Se sostiene

\section{ABSTRACT}

This article is about the extent of interpretation of the crime in delivering false information, as described in art. 59 a) of Stock Market Law, specifically in connection with the object of falsehood. It is stated that only the delivery of false information relevant to the price of the stocks fulfills the typical requirements for the legal description of the crime. Therefore, the delivery of any other kind of false information - specially required from the Superintendencia de Valores, excecuting its duty of inspection and control - but unable to influence the price of the stocks, remains outside the field of application of the legal description. Based on these premises, the

ReCibido el 7 de mayo y APROBADO el 30 de junio de 2017

* Doctor en Derecho (Friburgo de Brisgovia), Profesor Titular de Derecho penal de la Universidad Diego Portales. Dirección postal: Av. República 112, Santiago de Chile. Correo electrónico: hector.hernandez@udp.cl. 
con ello que el art. 59 letra a) de la Ley de Mercado de Valores constituye una tipificación general en el derecho chileno de las llamadas manipulaciones informativas de precios o de mercado. La tesis se ve reforzada por la consideración de las distorsiones valorativas que la lectura contraria provocaría en el sistema de los delitos contra las facultades de investigación o fiscalización en el derecho chileno.

\section{Palabras claves}

Delitos de la Ley de Mercado de Valores - Información falsa al mercado Manipulación informativa-Obstrucción a la fiscalización.
Author states that the art. 59 a) of Stock Market Law is a general description in the-Chilean Law - about the information-based manipulation of the prices, or the market. The thesis becomes stronger, by taking into consideration the resulting valuation distortions that the opposite interpretation could provide to the criminal activity against the investigation and control faculties existing in the Chilean Law.

KEYwords
Stock Market Crimes -
False information to the Market
- Manipulation of Information -
Obstruction to inspection and control.

\section{EL PROBLEMA}

Una de las disposiciones penales más relevantes de la Ley $\mathrm{N}^{\circ} 18.045$ sobre Mercado de Valores es la del art. 59 letra a) ${ }^{1}$, que en lo fundamental contiene la figura de información falsa más amplia que exhibe la ley, referida a los que proporcionen "antecedentes falsos" a la Superintendencia de Valores y Seguros (en lo sucesivo, sólo la Superintendencia), a una bolsa de valores o al público en general, "para los fines de lo dispuesto en esta ley"2.

La amplitud de los términos del precepto, en particular en lo que concierne a los "antecedentes" sobre los que puede recaer la falsedad, permitirían a primera vista una interpretación sumamente amplia del tipo penal, que incluyera la entrega de cualquier clase de antecedentes falsos, aun de aquéllos carentes de todo significado para la cotización de valores en el mercado, por ejemplo, información falsa sobre el comportamiento de un sujeto en el contexto de una fiscalización de la Superintendencia con fines de sanción. Si bien los casos en que se ha impuesto pena en virtud del art. 59 letra a) se refieren inequívocamente a la entrega de información falsa relevante para la cotización de ciertos valores ${ }^{3}$, no puede descartarse

${ }^{1}$ En lo sucesivo, artículos sin otra mención corresponden a los de esta ley.

2 El precepto es del siguiente tenor: "Art. 59. Sufrirán las penas de presidio menor en su grado medio a presidio mayor en su grado minimo: a) Los que maliciosamente proporcionaren antecedentes falsos o certificaren hechos falsos a la Superintendencia, a una bolsa de valores o al público en general, para los efectos de lo dispuesto en esta ley".

3 Véanse las condenas en los casos "Serrano" (sentencia del $4^{\circ}$ Tribunal Oral 
que los términos de la ley alimenten la pretensión de obtener lo mismo respecto de la entrega de información falsa de cualquier naturaleza.

No parece ser ésa, sin embargo, una lectura correcta de la ley. Al margen de que resulte conveniente reprimir también la entrega de antecedentes falsos sin incidencia en la cotización de valores en el contexto del funcionamiento de un mercado intensamente regulado como es el mercado de valores, en particular también para fortalecer la labor fiscalizadora de la autoridad competente en el sector, todo parece indicar que el art. 59 letra a) no es la disposición llamada a cumplir esa tarea.

La tesis que al respecto se quiere justificar en las páginas siguientes es que el art. 59 letra a) versa exclusivamente sobre antecedentes relevantes para la cotización de valores en el mercado de valores, de modo que constituye específicamente una tipificación penal de lo que se da en llamar manipulación informativa del mercado o, al menos, en la antesala de tales formas de manipulación de mercado, y no un delito genérico de falsedad, en particular, no un delito que pudiera caracterizarse como de simple "obstrucción a la fiscalización" de la Superintendencia.

Por último, esta tesis debiera ser válida también para la inteligencia de la enigmática figura del art. 59 letra f ${ }^{4}$, que al parecer pretende hacerse cargo

en lo Penal de Santiago, de 15 de diciembre de 2014, RIT No 267-2014, validada por sentencia de la Corte de Apelaciones de Santiago, de 28 de abril de 2015, Rol $N^{\circ}$ 558-2015), "La Polar" (sentencia del $2^{\circ}$ Juzgado de Garantía de Santiago, de 18 de diciembre de 2015, RIT N 6930-2011) y "FIT" (sentencia del $4^{\circ}$ Juzgado de Garantía de Santiago, de 4 de abril de 2017, RIT No 7150-2015). Lo mismo rige para el caso "ALFA", que terminó en absolución respecto de los tipos de la Ley de Mercado de Valores, básicamente por consideraciones probatorias (sentencia del $3^{\circ}$ Tribunal Oral en lo Penal de Santiago, de 13 de febrero de 2013, RIT N 174-2012, validada en esta parte por sentencia de la Corte de Apelaciones de Santiago, de 6 de junio de 2013, Rol N 484-2013, un detallado análisis del caso puede verse en MoREIRA, Alejandro, Comentario a sentencias dictadas en caso ALFA por delitos concursales, infracción al mercado de valores y obtención fraudulenta de crédito, en Revista Jurídica del Ministerio Público 59 [2014], pp. 223 ss.) y para el caso "CB", que también terminó en absolución por razones probatorias y atingentes al concepto de falsedad (segunda sentencia absolutoria del $3^{\circ}$ Tribunal Oral en lo Penal de Santiago, de 3 de abril de 2017, RIT N² 217-2016), si bien debe reconocerse que en este segundo caso los acusadores pusieron especial énfasis en la circunstancia de que se mintiera (aunque sobre información económicamente relevante) en una diligencia de fiscalización.

${ }^{4}$ Del siguiente tenor: "Art. 59. Sufrirán las penas de presidio menor en su grado medio a presidio mayor en su grado minimo: f) Los directores, administradores y gerentes de un emisor de valores de oferta pública, cuando efectuaren declaraciones maliciosamente falsas en la respectiva escritura de emisión de valores de oferta pública, en el prospecto de inscripción, en los antecedentes acompañados a la solicitud de inscripción, en las informaciones que deban proporcionar a las Superintendencias de Valores y Seguros o de 
de la entrega de información falsa en relación con los actos encaminados a la colocación de acciones de primera emisión, sin perjuicio de que la pena sea exactamente la misma, así como de las dudas fundadas sobre su estricta necesidad, atendido que los términos de la letra a) permiten cubrir perfectamente esos supuestos. 5 . Para los efectos de este trabajo se asumirá que se trata de una simple variante del art. 59 letra a), de modo que no se le volverá a tomar en consideración.

\section{Pena y Ubicación SISTEMÁtica: El ART. 59 LETRA}

\section{A) COMO TIPIFICACIÓN GENERAL DE LAS LLAMADAS MANIPULACIONES INFORMATIVAS}

La primera impresión que provocan los términos amplios del art. 59 letra a), favorable a una interpretación que abarque la entrega de cualquier antecedente falso, pierde buena parte de su plausibilidad cuando se considera tanto la posición prominente del precepto en el sistema de las disposiciones penales de la ley como la alta penalidad (privación de libertad de hasta diez años, esto es, pena de crimen) asociada a dicha posición tan destacada.

Si se hace abstracción por un momento de la letra a) y se mira el resto del art. 59 en su conjunto, se aprecia con nitidez que el artículo se hace cargo básicamente de dos grupos de casos de especial gravedad para el adecuado funcionamiento del mercado de valores: por una parte los supuestos de manipulación de precio o de mercado de la letra e) ${ }^{6}$ en relación con las prohibiciones de manipulación de los arts. 52 y $53^{7}$ y, por la otra,

Bancos e Instituciones Financieras en su caso, o a los tenedores de valores de oferta pública o en las noticias o propaganda divulgada por ellos al mercado".

${ }^{5}$ El tipo penal fue introducido mediante la Ley No 19.301, de 19 de marzo de 1994. La historia fidedigna del establecimiento de la ley (Boletín $\mathrm{N}^{\circ}$ 909-05) no da mayores señales al respecto.

${ }^{6}$ Que reza así: “Art. 59. Sufrirán las penas de presidio menor en su grado medio a presidio mayor en su grado minimo: e) Las personas que infrinjan las prohibiciones consignadas en los artículos 52, 53, inciso primero del artículo 85 y letras a), d), e) y h) del artículo 162 de esta ley".

$7 \mathrm{El}$ texto de ambos preceptos es el siguiente: "Art. 52. Es contrario a la presente ley efectuar transacciones en valores con el objeto de estabilizar, fijar o hacer variar artificialmente los precios. // Sin perjuicio de lo dispuesto en el inciso anterior, podrán efectuarse actividades de estabilización de precios en valores de acuerdo a reglas de carácter general que imparta la Superintendencia y únicamente para llevar adelante una oferta pública de valores nuevos o de valores anteriormente emitidos y que no habian sido objeto de oferta pública"; "Art. 53. Es contrario a la presente ley efectuar cotizaciones o transacciones ficticias respecto de cualquier valor, ya sea que las transacciones se lleven a cabo en el mercado de valores o a través de negociaciones privadas. // Ninguna persona 
hipótesis de falsedad en el objeto central de su función por parte de los principales gatekeepers llamados a controlar y garantizar el funcionamiento del mercado de valores (auditores, clasificadores de riesgo y, aunque tal vez su calificación como gatekeepers resulte exagerada, intermediarios de valores) de las letras b), c), d) y g) ${ }^{8}$.

Se trata, en consecuencia, de conductas especialmente graves que comprometen el funcionamiento del mercado de valores de un modo directo. Es en este contexto en que, como ya se ha sugerido, dejarse llevar por la aparente amplitud de la letra a) se torna especialmente problemático. Porque proporcionar antecedentes falsos en el contexto del funcionamiento del mercado de valores puede ser tanto una conducta de la mayor gravedad como una completamente nimia, dependiendo de una serie de factores muy diversos, de modo que, a pesar de que la ley no entrega mayores orientaciones, no parece que cualquier conducta que satisfaga formalmente la descripción legal sea digna del mismo tratamiento que merecen los casos recién indicados, al punto que resulte inverosímil que eso realmente responda al propósito de la ley.

Así las cosas, si la ley ha querido tratar conjuntamente todas estas hipótesis y asignarles las penas más graves que prevé en este ámbito de actividad, resulta razonable entender que existen semejanzas relevantes entre ellas, de modo que el supuesto de la letra a) en rigor debería estar más emparentado con los supuestos de los otros literales del artículo que lo que sugiere su amplio tenor literal.

Y, efectivamente, el supuesto de la letra a) tiene un parentesco profundo con las falsedades calificadas de los gatekeepers, pero también, lo que es más importante para los fines de este trabajo, con las hipótesis de manipulación de precios o de mercado.

En cuanto a lo primero, a pesar de tratarse a primera vista de un delito común (al referirse indiferenciadamente a "los que" incurran en la

podrá efectuar transacciones o inducir o intentar inducir a la compra o venta de valores, regidos o no por esta ley, por medio de cualquier acto, práctica, mecanismo o artificio engañoso o fraudulento".

${ }^{8}$ Del siguiente tenor: "Art. 59. Sufrirán las penas de presidio menor en su grado medio a presidio mayor en su grado minimo: b) Los administradores y apoderados de una bolsa de valores que den certificaciones falsas sobre las operaciones que se realicen en ella. // c) Los corredores de bolsa y agentes de valores que den certificaciones falsas sobre las operaciones en que hubieren intervenido. // d) Los contadores y auditores que dictaminen falsamente sobre la situación financiera de una persona sujeta a obligación de registro de conformidad a esta ley. // $g$ ) Los socios, administradores y, en general cualquier persona que en razón de su cargo o posición en las sociedades clasificadoras, se concertare con otra persona para otorgar una clasificación que no corresponda al riesgo de los títulos que clasifique”. 
conducta), una lectura más detenida demuestra que siempre se trata de la conducta de sujetos sobre los que pesan deberes especiales de información y consiguientes deberes de veracidad en razón de su cargo o posición en entes regulados, como se desprende de la circunstancia de que los antecedentes y las certificaciones relevantes para los efectos del tipo son aquéllos proporcionados o realizados "para los efectos de lo dispuesto en esta ley", es decir, que responden a deberes establecidos en la misma". Así las cosas, el art. 59 letra a) es en este sentido equivalente, por ejemplo, al delito de apropiación o distracción indebida del art. 470 No 1 del Código penal (en lo sucesivo, sólo $\mathrm{CP}$ ), que aunque también se refiere simplemente "a los que" incurran en las conductas de apropiación o distracción, reconocidamente sólo es aplicable a quienes (como verdadera condition préalable) han recibido previamente la cosa en cuestión en virtud de un título que obliga a entregarla o devolverla ${ }^{10}$. Si se trata en estos casos de delitos especiales stricto sensu o de una figura intermedia entre éstos y los delitos comunes, como la que algunos autores han dado en llamar "delitos de posición", que sin ser propiamente comunes no presentan particularidades en materia de "comunicabilidad" de las circunstancias personales ${ }^{11}$, es por cierto una cuestión discutible, pero no lo es que estos delitos tienen un status especial. Esto es, por lo demás, lo que permite distinguir razonablemente el art. 59 letra a) del art. 61 , con pena bastante más baja ${ }^{12}$ : el art. 61 es un delito

9 Sin contar con que esta interpretación también viene sugerida por la referencia a la "certificación" de hechos falsos en la misma letra a), pues sólo tiene sentido que certifiquen algo quienes ocupan una posición o tienen una función que de algún modo garantiza ante terceros la efectividad de un hecho. En la misma línea MorEIRA, Alejandro, Comentario, cit. (n. 3), p. 226 y TORRES, Angélica, El delito de entrega de información falsa al mercado como delito base o precedente de lavado de dinero, en Revista Jurídica del Ministerio Público 64 (2015), p. 202.

${ }^{10}$ Así, correctamente, GARRIDO, Mario, Derecho penal (Santiago, Editorial Jurídica de Chile, 2000) IV, p. 366. En general la literatura coincide en este punto, aunque no necesariamente se extraiga la consecuencia de que se está frente a delitos que, a menos que se hagan los matices del caso, difícilmente admiten la calificación de delitos "comunes".

${ }^{11}$ Sobre esto Robles Planas, Ricardo, Garantes y cómplices (Barcelona, Atelier, 2007), p. 129 ss., y antes RoBles Planas, Ricardo, La participación en el delito: fundamento y límites (Madrid - Barcelona, Marcial Pons, 2003), pp. 240 s.; una distinción alternativa puede verse en GÓmEz MARTín, Víctor, Los delitos especiales (Madrid, Edisofer, 2006), pp. 520 ss.

${ }^{12} \mathrm{El}$ art. 61 reza así: "Art. 61. Las personas que con el objeto de inducir a error en el mercado difundieren noticias falsas o tendenciosas, aun cuando no persiguieren con ello obtener ventajas o beneficios para si o terceros sufrirán las penas de presidio menor en sus grados minimo a medio. // La pena señalada en el inciso precedente se aumentará en un grado, cuando la conducta descrita la realice el que en razón de su cargo, posición, acti- 
común en el que puede incurrir cualquiera que difunde informaciones falsas o tendenciosas y lo hace deliberadamente, "con el objeto de inducir a error al mercado". Aunque no tenga deberes especiales ${ }^{13}$, la conducta es considerada per se intolerable, en la lógica tradicional de las figuras de agio $^{14}$, pero al mismo tiempo menos grave que la conducta equivalente cometida por sujetos especialmente obligados, precisamente por la ausencia de deberes especiales de información ${ }^{15}$.

Ahora bien, más que las restricciones que para la aplicación del tipo penal pudieran derivarse de la delimitación del círculo de sujetos relevantes, para los fines de este trabajo interesan especialmente aquellas restricciones concernientes al objeto sobre el cual ha de recaer la falsedad. Los deberes de información y veracidad en el contexto de mercados regulados

vidad o relación, en la Superintendencia o en una entidad fiscalizada por ella, pudiera poseer o tener acceso a información privilegiada".

${ }^{13}$ Esto no se ha visto modificado por la enigmática introducción del inciso segundo y su alusión a ciertos sujetos calificados mediante la Ley $\mathrm{N}^{\circ} 20.382$, de 20 de octubre de 2009, toda vez que quienes pueden contar con información privilegiada no tienen necesariamente deberes de información.

${ }^{14}$ Nótese la semejanza con la figura general de agio prevista en el art. 11 del Decreto Ley $\mathrm{N}^{\circ} 280$, de 24 de enero de 1974, sobre delito económico ("El que difundiere noticias falsas o tendenciosas, realizare operaciones ficticias, simulare actos o contratos, o utilizare cualquier otro medio fraudulento, para alterar la normalidad del abastecimiento o los precios de los articulos esenciales, la estabilidad de la moneda, de los valores o efectos públicos negociados en las Bolsas de Comercio, o del régimen económico nacional, sufrirá la pena de presidio mayor en cualquiera de sus grados'), que fue derogado poco tiempo después de la dictación de la Ley $\mathrm{N}^{\circ} 18.045$ (mediante el art. 12 de la Ley No 18.223, de 10 de junio de 1983). Sobre el agio en el Decreto Ley $\mathrm{N}^{\circ}$ 280 Llanos, Hugo, El Decreto Ley No 280, sobre delito económico, en Revista Chilena de Derecho 1 (1974), pp. 108 s.; y CURY, Enrique, El Decreto Ley No 280, sobre delito económico, en Revista Chilena de Derecho 1 (1974), pp. 654 s. Sobre la conexión de estas figuras con las disposiciones de la Ley de Mercado de Valores, incluyendo en el mismo contexto la figura de alteración del precio natural del trabajo, géneros o mercaderías del art. 285 CP, LoNDOÑo, Fernando, Aproximación histórico-comparada al Titulo VIII de la Ley de Mercado de Valores: bases para el reconocimiento de un contenido anti-manipulativo, en Politica Criminal 20 (2015), pp. 402 ss.

${ }^{15}$ Vería distinto el asunto GarCía, Gonzalo, Equivalentes funcionales en los delitos económicos. Una aproximación de solución ante la falta de lesividad material en delitos de presentación de información falsa al mercado de valores, en Politica Criminal 23 (2017), p. 194, quien parece entender que la diferencia entre ambos preceptos radicaría en que sólo el art. 61 obedecería a la lógica de la manipulación informativa, en tanto que el art. 59 a) respondería a otra lógica, la que, sin embargo, queda sin explicitación. Desde ya se le puede objetar que si fuera ésa efectivamente la diferencia entre las dos figuras se daría la paradoja de que el supuesto más específico, más exigente y en principio más grave de entrega de información falsa merecería menos pena que la figura genérica y (supuestamente) menos exigente. 
son muchos y de alcances muy variados, de modo que la gravedad de su infracción es también muy dispar. No es razonable pensar que el art. 59 letra a), aunque tenga como destinatarios sólo a sujetos especialmente obligados, reprima de modo indiferenciado la entrega de cualquier clase de antecedente falso y que haga de eso una de las figuras centrales y más graves del derecho penal del mercado de valores. Más bien al contrario, la prominencia y gravedad que se le asigna a la conducta típica lleva a pensar que, tal como ocurre en general con los supuestos tipificados en el art. 59, también en este caso la ley sólo reprime la entrega de información falsa cuando, en atención al objeto sobre el que recae la falsedad, la conducta constituye un atentado especialmente grave contra el funcionamiento del mercado de valores.

Tal parece ser el caso sólo cuando la falsedad recae sobre antecedentes relevantes para la cotización de valores en el mercado, pues sólo en ese caso se atenta directamente contra el mercado de valores (y no sólo mediatamente, a través del ataque contra la fiscalización de dicho mercado) y de un modo equiparable en gravedad al del resto de los supuestos recogidos en el art. 59, porque bajo esa exigencia la conducta resulta equiparable a la de manipulación de precios o mercado del art. 59 letra e) en relación con los arts. 52 y 53 . Concretamente, se deja entender como una hipótesis de "manipulación informativa" de precios o mercado, o al menos como una figura en la antesala de dichas formas de manipulación, lo que supone, en todo caso, que debe tender objetivamente hacia (o al menos ser idónea para) la alteración del precio de los valores, en el sentido de que los antecedentes en cuestión tengan la capacidad potencial de incidir en el precio de tales valores.

Antes de seguir, si bien no incide en la corrección de la interpretación propuesta, conviene detenerse aquí en la cuestión, más terminológica que conceptual, de si realmente puede considerarse que la entrega al mercado de antecedentes falsos relevantes para el precio de ciertos valores representa, por sí misma, una hipótesis de manipulación de mercado, concretamente una de las llamadas "manipulaciones informativas".

Como se sabe, los casos de manipulación de precios o de mercado, esto es, la alteración ilícita del precio de los valores transados en el mercado constituyen universalmente uno de los dos pilares ${ }^{16}$ sobre los que se construye el moderno derecho penal del mercado de valores. En ese contexto

${ }^{16}$ El otro es el de las conductas relativas a la información privilegiada. Ambos pilares dan lugar a lo que genéricamente se conoce hoy como "abuso de mercado". $\mathrm{Al}$ respecto, el conciso pero interesante panorama que ofrecen SIEMS, Mathias - NELEMANS, Matthijs, The Reform of the EU Market Abuse Law: Revolution or Evolution?, en Maastricht Journal of European and Comparative Law 19 (2012), pp. 195 ss. 
se suele distinguir entre manipulaciones mediante acciones (action-based manipulations), una de cuyas variantes son las manipulaciones mediante transacciones en el mercado de valores mismo (trade-based manipulations), y manipulaciones mediante información o informativas (informationbased manipulations $)^{17}$. Pues bien, reconocido que existe algo así como una "manipulación informativa" en razón de que ciertas informaciones pueden incidir en el precio de los valores, parece evidente que se pueda situar la entrega de información relevante falsa "en el campo" de tal tipo de manipulaciones. Esto lo ha reconocido la literatura especializada, también, al menos en parte, entre nosotros ${ }^{18}$, y debiera ser lo normal que la entrega de ese tipo de información constituya en los hechos una manipulación informativa, como quiera que se defina ésta.

El único escrúpulo atendible para no caracterizar la figura del art. 59 letra a) derechamente como una tipificación genérica de manipulación informativa radica en que es manifiesto que el precepto en cuestión no exige efectiva incidencia en el precio de ningún valor, es decir, no exige efectiva "manipulación" ni tampoco ningún propósito manipulativo. Este dato es indudable, pero no parece ser decisivo para negarle el carácter de manipulación informativa a la conducta descrita por la disposición, pues es conocida la tendencia en el derecho comparado, específicamente en los ordenamientos modélicos, a tipificar tal manipulación como un delito de peligro y de mera actividad, que es precisamente lo que sería el art. 59 letra a).

En efecto, tanto en el derecho federal de los Estados Unidos como en el derecho de la Unión Europea se prescinde de un efectivo resultado consistente en la alteración del precio de los valores y se hace bastar la sola entrega de una información falsa. Así, en el derecho estadounidense

17 Sobre estas distinciones y subsecuentes clasificaciones, que admiten múltiples variables y superposiciones (así, por ejemplo, se puede decir que toda acción implica información), Allen, Franklin - Gale, Douglas, Stock-price Manipulation, en The Review of Financial Studies 5 (1992) 3, pp. 505 ss.; en Chile Londoño, Fernando, Ilícito de manipulación bursátil: fenómeno y lesividad. Aspectos de política sancionatoria, en Politica Criminal 15 (2013), p. 86 con nota al pie 54.

${ }^{18}$ Londoño, Fernando, Ilícito de manipulación bursátil, cit. (n. 17), p. 85, quien considera en su análisis "tipos de falsedad ideológica, afines en sede objetiva a las modalidades de manipulación informativa" (énfasis en el original), entre los que cuenta el art. 59 letras a) y f). Y agrega: "las hipótesis de falsedad informativa de las letras a) y f) del art. 59 de la LMV - si bien insertas en cánones de figuras de mera falsedad informativa, no necesariamente manipuladoras del mercado secundario y primario, respectivamente - pueden muy bien asociarse a esta categoría [manipulación informativa]" (p. 105 con nota al pie 114). En contra, aparentemente, GARCíA, Gonzalo, Equivalentes funcionales en los delitos económicos, cit. (n. 15), pp. $194 \mathrm{~s}$. 
se tipifica como manipulación de mercado, entre otras, la conducta de "hacer... cualquier declaración que, al tiempo en que se hizo y a la luz de las circunstancias bajo las cuales se hizo, fuera falsa o engañosa respecto de cualquier hecho material"19 en relación con valores, en tanto que en el derecho de la Unión Europea se define como manipulación de mercado, entre otras, la conducta de "difundir información a través de los medios de comunicación, incluido internet, o por cualquier otro medio, transmitiendo asi o pudiendo transmitir señales falsas o engañosas en cuanto a la oferta, la demanda o el precio de un instrumento financiero, de un contrato de contado sobre materias primas relacionado o de un producto subastado basado en derechos de emisión, o pudiendo asi fijar en un nivel anormal o artificial el precio de uno o varios instrumentos financieros, de un contrato de contado sobre materias primas relacionado o de un producto subastado basado en derechos de emisión, incluida la difusión de rumores", así como la de "transmitir información falsa o engañosa o suministrar datos falsos en relación con un indice de referencia "20. En ambos casos se exige, por cierto, dolo (conocimiento del carácter falso de la información) o al menos alguna forma de culpa muy calificada por parte del agente ${ }^{21}$ y la norma estadounidense exige adicional y especialmente un comportamiento realizado "con el propósito de inducir a la compra o venta" de los valores en cuestión, pero en el plano objetivo basta con la entrega de la información falsa.

Las razones para prescindir de mayores exigencias tratándose de manipulaciones informativas responden a dos tipos de consideraciones: por una parte, la más obvia, el propósito de facilitar la prueba de las infracciones y la consiguiente efectividad de las prohibiciones; y por la otra, la circunstancia de que, a diferencia de lo que ocurre con las manipulaciones mediante transacciones, cuya delimitación respecto de transacciones legítimas que, sin embargo, inciden por fuerza en la cotización de los valores,

19 Sección 9(a)(4) de la Securities Exchange Act de 1934 (SEA 1934). Sobre este aspecto específico de la regulación estadounidense véase Loss, Louis - SELIGMAN, Joel - Paredes, Troy, Fundamentals of Securities Regulation ( $6^{\circ}$ edición, New York, Wolters Kluwer, 2011) II, pp. $1492 \mathrm{s.}$

${ }^{20}$ Art. 12.1, letras c) y d) del Reglamento (UE) No 596/2014, del Parlamento Europeo y del Consejo, de 16 de abril de 2014, sobre Abuso de Mercado. Sobre este aspecto del Reglamento puede verse MolOney, Niamh, EU Securities and Financial Markets Regulation ( $3^{\circ}$ edición, New York, Oxford University Press, 2014), pp. 740 ss.

${ }^{21}$ La disposición estadounidense exige "que la persona supiera o haya tenido motivo razonable para creer que era falsa o engañosa”, mientras que la norma europea sólo considera que hay manipulación "cuando el autor de la transmisión o del suministro de datos supiera o debiera haber sabido que eran falsos o engañosos" u otras fórmulas semejantes. 
resulta especialmente ardua, la entrega de antecedentes falsos relevantes para la cotización de valores es, en cambio, inequívocamente ilícita ${ }^{22}$. Es cierto que algunos ordenamientos nacionales reservan las sanciones penales para supuestos en los que la información falsa efectivamente provoca una alteración constatable del precio de los valores sobre los que versa la información $^{23}$, pero manifiestamente no es ésa la regla, de modo que no parece existir impedimento válido para caracterizar un delito de entrega de información falsa relevante para el mercado como uno de manipulación informativa ${ }^{24}$.

Ahora bien, en el caso chileno un posible argumento contra la restricción de los alcances del tipo a la información falsa referida exclusivamente a factores relevantes para el precio de los valores y, con ello, de su comprensión como tipificación general de manipulación informativa, podría ser que dicha exigencia tendría sentido respecto de la información que se entrega sólo al público en general, pero no respecto de aquélla que se entrega a un órgano fiscalizador como es la Superintendencia, que por cierto no requiere la información para tomar decisiones económicas. De ahí que, si la ley menciona especialmente a la Superintendencia entre los

22 Sobre razones para prescindir de resultado lesivo Londoño, Fernando, Aproximación histórico-comparada, cit. (n. 14), pp. 407 s.

${ }^{23} \mathrm{Tal}$ es el caso, por ejemplo, del derecho alemán, donde según el $\$ 39$ II Nr. 3 de la Ley de comercio de títulos-valores (Wertpapierhandelsgesetz-WpHG) constituye infracción administrativa la difusión dolosa o negligente de información falsa en contra de lo dispuesto en el $\$ 12$ de la ley en relación con los Arts. 15 y 12.1 letras c) o d) del citado Reglamento (EU) $N^{\circ} 596 / 2014$, en tanto que conforme al $₫ 38$ I WpHG constituyen delito las mismas conductas cuando son realizadas con dolo e inciden en el precio de bolsa o de mercado de ciertos instrumentos financieros y similares especialmente señalados. Esta situación es la que se encuentra vigente en Alemania desde el 1 de julio 2016, fecha de la entrada en vigor de la Primera Ley de actualización del mercado financiero (1. Finanzmarktnovellierungsgesetz - 1. FiMa$\mathrm{NoG}$ ), a consecuencia de las nuevas normas de la Unión Europea. En esto, sin embargo, la situación es fundamentalmente idéntica a la anterior. Una visión crítica de esta exigencia, ya bajo la regulación anterior a 2016, en Tiedemann, Klaus, Manual de derecho penal económico. Parte especial (varios traductores, Lima, Grijley, 2012), $\$ 9 \mathrm{n}^{\circ}$ marg. 353.

${ }^{24}$ De hecho, en la literatura alemana nadie le niega el calificativo de "manipulación de mercado" a la infracción administrativa que no requiere incidencia en el precio de los valores. Véase, entre otros (si bien respecto de la regulación anterior a 2016, que, sin embargo, como se ha dicho, en materia de manipulación de mercado es esencialmente la misma), Tiedemann, Klaus, Manual de derecho penal económico, cit. (n. 23), $\$ 9 \mathrm{n}^{\circ}$ marg. 347 ss.; y Sorgenfrei, Ulrich en Park, Tido (editor), Kapitalmarkt-Strafrecht. Handkommentar (Baden-Baden, Nomos, 2004), Börsendelikte $\$ \$ 20 \mathrm{a}, 38 \mathrm{I}$ Nr. 4, 39 WpHG (p. 210 ss.) y Ordnungswidrigkeiten $\$ 39$ I Nr. 1, 2 IV WpHG (p. 657). 
posibles destinatarios de la información falsa típica, cabría suponer que ésta es cualquiera que pueda ser de interés para los fines de la autoridad fiscalizadora. Pero con ello se estaría pasando por alto que la Superintendencia tiene también importantes funciones de garante de la información divulgada al mercado, como se desprende, por ejemplo, del art. $4^{\circ}$ letra e) del Decreto Ley (DL) No 3.538, de 23 de diciembre de 1980, Ley Orgánica de la Superintendencia, que, junto con prever su facultad de fijar las normas para la confección y presentación de estados financieros, prevé que pueda ordenar la rectificación de partidas de la contabilidad, o especialmente, del art. 23 del mismo cuerpo normativo, donde, junto con el establecimiento del deber de reserva de sus funcionarios respecto de los documentos y antecedentes no públicos de los sujetos fiscalizados, dispone en su inciso segundo que esto "no obstará a que el Superintendente pueda difundir o hacer difundir por las personas y medios que determine, la información o documentación relativa a los sujetos fiscalizados con el fin de velar por la fe pública o por el interés de los accionistas, inversionistas y asegurados". Es por esta razón que es de toda lógica que se considere a la Superintendencia como un destinatario muy relevante de las informaciones típicas, aun cuando éstas sean sólo aquéllas con incidencia en el precio de los valores.

En rigor, el único inconveniente que podría acarrear la calificación de la entrega de información falsa relevante como manipulación informativa sería que, en virtud de dicha calificación, se pretendiera establecer interpretativamente exigencias que dejaran sin efecto los propósitos que en general subyacen a la formulación de un tipo penal de mera actividad y de peligro, como una posible exigencia de resultado, por mucho que ésta parezca totalmente incompatible con el texto legal, o, más plausible, una exigencia de ciertos propósitos manipulativos ${ }^{25}$. Pero precisamente si se tienen presentes las razones que justifican en esta materia específica la prescindencia de tal resultado y propósito, el peligro debería estar conjurado. Una cosa muy distinta es, en cambio, que en razón de la prominencia del tipo penal y el contexto sistemático en que se encuentra alojado, se exija que la información falsa en cuestión tenga siquiera un mínimo potencial para incidir en el precio de valores que se transan en el mercado, aunque en el derecho chileno, a diferencia de lo que, según se ha visto, ocurre en el derecho comparado, esto no se diga expresamente.

Más aún, el art. 59 letra a) parece ser la vía natural para capturar de modo sencillo y eficaz las hipótesis de manipulación informativa en la ley

${ }^{25}$ Véanse, por ejemplo, las justificadas objeciones que plantea LondoÑo, Fernando, Aproximación histórico-comparada, cit. (n. 14), pp. 423, 432 s. y 444 s. frente a una eventual re-interpretación de los tipos de falsedad de las letras a) y f) del art. 59 en clave de "fraude". 
chilena, pues si bien es posible que éstas se encuentren envueltas tanto en el ya mencionado delito residual del art. 61, como también en el oscuro art. 53, al que se remite el art. 59 letra e), que prohíbe "inducir o intentar inducir a la compra o venta de valores, regidos o no por esta ley, por medio de cualquier acto, práctica, mecanismo o artificio engañoso o fraudulento ${ }^{226}$, el delito de entrega de antecedentes falsos ofrece, con la misma pena, una cobertura amplia y expedita para ellas, sin las dudas interpretativas que lastran la inteligencia del art. 59 letra e).

Como se ve, la calificación de la conducta del art. 59 letra a) como una manipulación informativa a secas o como una manipulación informativa "en sentido amplio" o como una conducta "en la antesala" de las manipulaciones informativas es una cuestión más bien terminológica que, aclarados los términos de la discusión, no debiera incidir en la corrección de la tesis de este artículo. Lo realmente importante es reiterar que, de aceptarse un alto grado de parentesco y hasta de superposición entre las manipulaciones informativas y el tipo de información falsa del art. 59 letra a), debería aceptarse también que la conducta típica de este último debe tender objetivamente hacia (o al menos ser idónea para) la alteración del precio de los valores, en el sentido de que los antecedentes en cuestión tengan la capacidad potencial de incidir en el precio de los valores, requiriéndose en el plano subjetivo exclusivamente el conocimiento del potencial de incidencia de los antecedentes falsos en dicho precio ${ }^{27}$.

Como ya se ha dicho, que se pueda situar el art. 59 letra a) "en el campo" de las manipulaciones informativas es algo que ya ha sido visto por parte de la literatura especializada, de modo que aquí no se está diciendo nada realmente novedoso al destacarlo. Lo único eventualmente novedoso es dar (o más bien explicitar) el paso siguiente y entender que el art. 59 letra a) no es un "cajón de sastre" que permite capturar la entrega de cualquier antecedente falso, sino que es sólo (y no: también) una tipificación en ese "campo", lo que supone la ya reiteradamente postulada restricción de los

${ }^{26}$ Sobre las manipulaciones por transacciones, parece claro que tienen su domicilio en el art. 52 y, en parte, en el art. 53, a los que remite el art. 59 letra e).

${ }^{27}$ En contra, aparentemente, García, Gonzalo, Equivalentes funcionales en los delitos económicos, cit. (n. 15), pp. 194 s. Se dice "aparentemente" porque, por una parte, su visión de que las manipulaciones informativas se encuentran exclusivamente en el art. 61 lleva al autor a situar otras hipótesis de entrega de información falsa, en particular el art. 59 letra a), en una zona desconectada del subsistema organizado (ámbito organizado, unidad funcional) de formación de precios y conectada con otras "unidades funcionales basadas en la confianza institucional", sin que, por otra parte, se explicite cuáles serían éstas. Podría tratarse de los "sistemas de supervisión del cumplimiento normativo" (p. 182, con referencia a la Superintendencia), pero lo cierto es que el punto no se resuelve explícitamente. 
antecedentes relevantes a aquéllos que tengan la capacidad de incidir en el precio de los valores que se transan en el mercado, es decir, que versen sobre factores determinantes o condicionantes de ese precio.

La consecuencia es que no satisfacen las exigencias del art. 59 letra a) los supuestos de informaciones falsas sin incidencia en los precios de los valores, aunque exista deber de entregarlas $y$, naturalmente, de ser veraces a su respecto. Hay muchas informaciones que se requieren no en razón de los valores mismos o de las operaciones que se realizan a su respecto, sino que con fines de control, de mejoramiento de gobiernos corporativos, de prevención de conflictos de interés, etc. Al margen de la importancia de estos aspectos y de la legitimidad intrínseca de una reacción penal frente a las falsedades a su respecto, la eventual entrega de antecedentes falsos atingentes a ellos, pero que no inciden en el precio de los valores que se transan en el mercado, no es subsumible en el art. 59 letra a).

$\mathrm{El}$ art. 59 letra a) no contiene, en consecuencia, un delito genérico de falsedad ni, en particular, una suerte de delito de "obstrucción a la fiscalización" de la Superintendencia mediante falsedad. A las razones positivas que se acaban de dar, a las que se agregará la evidencia en cuanto a que en el derecho comparado no se mezclen los tipos de manipulación informativa o de entrega de antecedentes falsos al mercado con las eventuales disposiciones penales en defensa de las facultades de fiscalización (infra IV), se debe sumar el sinsentido que representaría en el sistema del derecho penal chileno la pretensión de que el art. 59 letra a) pudiera ser "también" un delito que protege la fiscalización en cuanto tal. A esto se dedica el apartado siguiente.

\section{EL SINSENTIDO DE ENTENDER EL ART. 59 LETRA A) COMO DELITO DE “OBSTRUCCIÓN A LA FISCALIZACIÓN” MEDIANTE}

FALSEDAD

La entrega de información falsa, especialmente a la Superintendencia, puede afectar por cierto las posibilidades de fiscalización de esta autoridad, y esto con total abstracción del significado de la información concreta para el precio de los valores. La cuestión a dilucidar es si tal afectación es relevante para los efectos del art. 59 letra a).

$\mathrm{Al}$ margen de que, como se verá infra IV, resulte a lo menos inusual reunir en un mismo precepto legal un tipo de manipulación de precios o de mercado con un tipo de protección de la fiscalización, la cuestión a resolver es si resulta plausible esta reunión desde la perspectiva más general de los delitos que reprimen la entrega de antecedentes falsos a los órganos públicos de fiscalización o investigación. 
Y es bastante obvio que, desde la lógica de la pura represión de las falsedades perpetradas ante órganos públicos con facultades fiscalizadoras, no parece tener sentido que la presentación de antecedentes falsos a la Superintendencia tenga indiferenciadamente más pena que la presentación de antecedentes falsos en un proceso judicial, incluso en un proceso judicial en materia penal (por crimen o simple delito) ${ }^{28}$, donde están comprometidos directa y dramáticamente tanto la libertad de las personas como el ejercicio del ius puniendi estatal, pues, como se sabe, en tal caso la pena es de presidio menor en su grado medio a máximo, o derechamente presidio menor en su grado máximo en el supuesto más grave de todos, como es que los antecedentes tiendan a perjudicar la posición del imputado o acusado (art. $207 \mathrm{CP}$ ), pena mayor que, sin embargo, sigue estando por debajo de la prevista por el art. 59 letra a ${ }^{29}$.

Y mucho menos sentido hace semejante penalidad si ahora se considera en la comparación el tratamiento de la presentación de antecedentes falsos al Ministerio Público, en el contexto de una investigación criminal. En efecto, la aportación de tales antecedentes y, en todo caso, a condición de que con ello se "obstaculice gravemente el esclarecimiento de un hecho punible o la determinación de sus responsables", tiene asignada por regla general la pena de presidio menor en su grado mínimo y multa, la que se aumenta en un grado en el caso extremo en que, además de ser tendencialmente perjudiciales para una persona en particular, conduzcan al Ministerio Público a solicitar medidas cautelares o a deducir una acusación infundada contra dicha persona (art. 269 bis CP), pena máxima posible que se ubica un grado por debajo del mínimo del marco previsto por el art. 59 letra a). Simplemente no hace ningún sentido que la entrega de antecedentes falsos a la Superintendencia tenga asignada per se una pena mucho mayor.

El marco penal del art. 59 letra a) sólo tiene sentido si éste no es un tipo penal de simple perturbación genérica de las pretensiones informativas de la autoridad en el mercado de valores, sino que se le concibe como un supuesto de manipulación informativa, lo que supone que la información falsa es de un tipo idóneo para incidir en el precio de determinados valores en el mercado, lo que es coherente con la circunstancia de que la ley, como ya se ha vista supra II, contemple la misma pena para las demás formas características de manipulación de mercado en el art. 59 letra e), en referencia a las prohibiciones de los arts. 52 y 53.

${ }^{28}$ Cuando se juzga una falta la pena es de presidio menor en su grado mínimo a medio, lo mismo que rige para las causas civiles.

${ }^{29}$ La única hipótesis prevista en el art. 207 CP que alcanza y eventualmente supera en penalidad al art. 59 letra a) es la del delito funcionario que puede cometer ni más ni menos que el fiscal del Ministerio Público que incurra en la conducta. 
Abona esta visión sistemática y echa por tierra el posible argumento en contra basado en que, por las razones que fuera, al legislador le parecen más importantes y dignas de protección penal las facultades fiscalizadoras de Superintendencia consideradas en sí mismas, la existencia de otras disposiciones penales que se encargan inequívoca y específicamente de la protección penal de tales facultades, todas las cuales indefectiblemente prevén penas menores que las previstas en el art. 59 letra a).

Tal es el caso, por ejemplo, del tipo penal del art. 60 letra j), mediante el cual se castiga con penas de presidio menor en cualquiera de sus grados, al que "...deliberadamente elimine, altere, modifique, oculte o destruya registros, documentos, soportes tecnológicos o antecedentes de cualquier naturaleza, impidiendo o dificultando con ello la fiscalización de la Superintendencia'30. Como es obvio, se trata de un tipo penal cuya razón de ser es la protección de las facultades de fiscalización de la Superintendencia. Lo interesante es que, en la línea general de las valoraciones del sistema, no se prevén para este supuesto las penas más altas del art. 59, sino sólo las más moderadas del art. 60. Y debe destacarse especialmente, porque desde la perspectiva de un supuesto delito de "obstrucción de las facultades fiscalizadoras" la figura del art. 60 letra j), consistente en la alteración, destrucción u ocultamiento de soportes informativos ${ }^{31}$ de los cuales la autoridad debería poder valerse para el ejercicio de sus funciones, con independencia de la colaboración de las personas que tienen la información relevante en su poder y con independencia asimismo del tiempo transcurrido, bien podría considerarse más grave que la simple entrega de información falsa o incompleta ante requerimientos de la misma ${ }^{32}$.

${ }^{30}$ El texto original, introducido mediante la Ley $\mathrm{N}^{\circ} 19.705$, de 20 de diciembre de 2000, era del siguiente tenor: "El que deliberadamente oculte o elimine los registros contables o de custodia de un intermediario de valores". Fue reemplazado mediante la Ley $\mathrm{N}^{\circ} 20.190$, de 5 de junio de 2007.

31 Si bien el concepto de "antecedentes" no se identifica necesariamente con documentación u otro tipo de soporte informativo y puede aplicarse también a la información en cuanto tal, en tanto que el verbo "ocultar" admite una lectura amplia que puede abarcar la simple omisión de informar, es contextualmente evidente que la letra j) del art. 60 se refiere a conductas que no recaen sobre la información en cuanto tal, sino sobre los soportes que la contienen, no sólo porque la ley menciona los "antecedentes de cualquier naturaleza" exclusivamente para completar la enumeración de "registros, documentos, soportes tecnológicos", sin alterar su sentido, sino además porque cuatro de los cinco verbos que emplea simplemente no son aplicables a la información en cuanto tal (no es posible eliminarla, destruirla, alterarla o modificarla en cuanto tal) en tanto que la primera acepción del quinto (ocultar) es de marcado carácter material, por lo que resultaría del todo desleal con la letra de la ley atribuirle precisamente el alcance que transforma por completo el sentido general del tipo.

${ }^{32}$ Según se desprende de la formulación de cargos, lo único que se le imputa 
Pero sin duda la más significativa de las disposiciones destinadas a proteger las facultades fiscalizadoras de la autoridad administrativa en esta materia y la que tiene los efectos más demoledores para la pretensión de ver en el art. 59 letra a) un tipo de esas características, es la del inciso tercero del art. 26 del DL N³ 3.538 de 1980, Ley Orgánica de la Superintendencia, conforme al cual "(l)as personas que rindan declaraciones falsas ante la Superintendencia incurrirán en las penas que establece el artículo 210 del Código Penal'33.

Pues bien, como se sabe, la pena prevista en el art. $210 \mathrm{CP}$ es de presidio menor en sus grados mínimo a medio, es decir completamente por debajo del marco penal del art. 59 letra a), lo que parece a todas luces absurdo tratándose de una figura específica y calificada de comportamiento inveraz ante la autoridad. Porque debe tenerse presente que para el derecho penal chileno las declaraciones inveraces se consideran en general como más graves que la aportación genérica de antecedentes falsos, o a lo más se consideran como igualmente graves, pero en ningún caso como menos graves que los supuestos genéricos, pues, como es obvio, una declaración ante la Superintendencia no es más que una manera específica, especialmente regulada, de aportarle antecedentes a ésta.

En efecto, si bien las penas previstas para la presentación de antecedentes falsos ante un tribunal conforme al art. $207 \mathrm{CP}$ son idénticas a las previstas para el falso testimonio en el mismo contexto (art. 206 CP), fuera del ámbito jurisdiccional, esto es, en el ámbito de la interacción con autoridades del ámbito administrativo, sólo se prevé un delito de declaraciones falsas, el perjurio del art. $210 \mathrm{CP}$, sin que se considere un delito genérico de entrega de antecedentes falsos. La única excepción en el ámbito extra-jurisdiccional es la regulación de la llamada obstrucción de la investigación, en el ya mencionado art. 269 bis CP, que equipara

al director en el contexto que importa a este trabajo es haber omitido mencionar la sociedad en la que, según la Superintendencia, tendría participación y de la cual sería beneficiario final.

${ }_{33}$ Disposición que debe entenderse en conjunto con la de la letra h) del art. $4^{\circ}$ del mismo texto legal, referido a las atribuciones generales de la Superintendencia: "Citar a declarar a los representantes, administradores, asesores y dependientes de las entidades o personas fiscalizadas y a toda otra persona que hubiere ejecutado y celebrado con ellas actos y convenciones de cualquiera naturaleza, respecto de algún hecho cuyo conocimiento estime necesario para el cumplimiento de sus funciones. Podrán ser citadas a declarar personas que sin ser fiscalizadas o relacionadas a ellas, ejecuten o celebren actos $o$ convenciones cuyo objeto sean instrumentos o valores emitidos por entidades fiscalizadas. No estarán obligadas a concurrir a declarar las personas indicadas en el artículo 361 del Código de Procedimiento Civil, a las cuales la Superintendencia, para los fines expresados en el inciso precedente, deberá pedir declaración por escrito". 
todas las formas de aportación de antecedentes falsos, pero, como se ha destacado, ni más ni menos que en el ámbito de la investigación criminal.

Asumir entonces que el art. 59 letra a) se aplica respecto de cualquier caso de presentación de antecedentes falsos a la Superintendencia, cualquiera sea la naturaleza y los posibles efectos de dicha información, implica aceptar una inconsistencia valorativa y sistemática monumental, consistente en que se castigue más severamente la aportación genérica de antecedentes falsos que las declaraciones falsas, o dicho en términos inversos, que el legislador quiso privilegiar, y muy significativamente, a quien en vez de enviar documentación con información falsa, presta formalmente declaración mendaz ante la autoridad, lo que sin duda resulta disparatado.

Nada tiene de disparatado, en cambio, que el legislador reprima con especial dureza la aportación de información falsa cuando dicha información es de una naturaleza tal que puede influir en el precio de valores que se transan en el mercado. Como se ha venido insistiendo, el art. 59 letra a) no constituye una tipificación de atentados contra las facultades fiscalizadoras de la Superintendencia, sino la tipificación de supuestos de manipulación informativa del mercado.

Ahora bien, contra este argumento basado en el inciso tercero del art. 26 de la Ley Orgánica de la Superintendencia, eventualmente se podría querer hacer valer una aplicación preferente del art. 59 letra a) en casos de declaraciones prestadas a propósito de asuntos atingentes al mercado de valores, por ejemplo, sobre la base de la especial relevancia de las facultades de la Superintendencia en el ámbito específico del mercado de valores o algo semejante. Sin embargo, tal línea argumental no resulta plausible a la luz de la historia fidedigna del establecimiento del art. 59 letra a).

Pues que el art. 26 del DL No 3.538 y el art. 59 letra a) estén en cuerpos legales separados se debe exclusivamente a una casualidad, ya que originalmente estaban destinados a estar uno al lado del otro. En efecto, el actual art. 26 del DL N 3.538 venía previsto como art. 57 en el Proyecto original de lo que llegaría a ser la Ley $\mathrm{N}^{\circ} 18.045$, enviado por el Presidente de la República a la Junta de Gobierno mediante Mensaje de 30 de diciembre de 1980, justo antes del artículo que contenía y contiene el actual art. 59 letra a), ambos preceptos con una redacción prácticamente idéntica a la que presentan hoy ${ }^{34} \mathrm{y}$, lo más importante para el ejercicio valorativo propuesto, con las mismas penas que hasta la actualidad exhiben.

${ }^{34}$ Así rezaban ambos preceptos: "Artículo $57^{\circ}$ (Declaraciones falsas a la Superintendencia). Las personan que rindan declaraciones falsas ante la Superintendencia, incurrirán en las penas que establece el artículo 210 del código Penal"; "Artículo $58^{\circ}$ (Penalidad para la falsedad y fraude). Sufrirán las penas de presidio menor en su grado medio a presidio mayor en su grado mínimo: (a) Los que maliciosamente proporcionaren 
Es evidente, en consecuencia, que el legislador de la época entendía que ambas figuras se referían a cuestiones diferentes que merecían un tratamiento penal igualmente diferente, lo que por lo demás se expresa también en los epígrafes que encabezaban cada precepto: "Declaraciones falsas a la Superintendencia" en un caso y "Penalidad para la falsedad y fraude" en el otro ${ }^{35}$. Esa comprensión se mantuvo hasta el final del proceso legislativo, pues, según se lee en el Informe de la Primera Comisión Legislativa de la Junta, de 23 de septiembre de 1981, el actual art. 26 sólo se eliminó del proyecto por la sencilla razón de estar incluido entre las modificaciones a la Ley Orgánica de la Superintendencia, previstas en el proyecto de ley sobre Sociedades Anónimas que se tramitaba en la misma época $^{36}$. La decisión sistemática confirma la idea de que la protección de las facultades fiscalizadoras de la Superintendencia es una cuestión que en cuanto tal no atinge directamente a la regulación material del mercado de valores, sino sólo indirectamente, razón por la cual se disciplina sólo a propósito de la organización de la fiscalización ${ }^{37}$.

Por último, refuerza la idea de que se está frente a un tipo de manipulación informativa en sentido amplio y no frente a uno de simple falsedad ante la autoridad, la circunstancia de que la ley prevea un círculo amplio de destinatarios de la información, siendo la Superintendencia sólo uno entre otros. Esto siempre fue así, pero no puede dejar de mencionarse que en el texto original del surgimiento de la normativa el año 1981, el círculo se restringía a la Superintendencia y a las bolsas de valores. Ya la mención a estas últimas permitía sostener que se trataba de un precepto que no versaba sobre la relación burocrática entre la autoridad y los administrados, pero es indudable que esta idea recibió un espaldarazo definitivo con la inclusión en el círculo de destinatarios del "público en general" mediante la Ley $\mathrm{N}^{\circ} 18.660$, de 20 de octubre de 1987. Y esto resulta decisivo, pues

o certificación a la Superintendencia o a una bolsa de valores, en su caso, para los efectos de lo dispuesto en esta ley, antecedentes falsos".

${ }^{35}$ Historia de la Ley $N^{\circ} 18.045$ (elaborada por la Biblioteca del Congreso Nacional), p. 30 (se cita la página del documento elaborado por la $\mathrm{BCN}$, no la de los documentos originales).

${ }^{36}$ Historia de la Ley $\mathrm{N}^{\circ} 18.045$, p. 70 . Que ambas disposiciones sea coetáneas echa por tierra cualquier posibilidad de argumentar que las valoraciones legislativas variaron con el tiempo, aumentando a ojos del legislador la importancia de la protección de las facultades fiscalizadoras de la Superintendencia, como sería de algún modo posible si el art. 59 letra a) fuera de data posterior.

${ }^{37}$ Que el legislador haya variado este criterio al introducir la letra j) del art. 60 que, como ya se dijo, es también un atentado contra la fiscalización, es algo que sí se puede explicar por el paso del tiempo: 20 años después el legislador ya no tiene la misma claridad sistemática, pero sin que esto cambie las conclusiones de fondo. 
todavía alguien podría estar dispuesto a sostener en términos absolutos que cualquier falsedad ante la Superintendencia en el contexto de las regulaciones del mercado de valores diera lugar a una reacción penal bajo el art. 59 letra a), cualquiera que fuera su potencial de lesividad, nada más que por mor del respeto debido a la autoridad; pero no poner restricciones respecto de informaciones dirigidas al público en general, por mucho que se trate de informaciones cuya entrega se halla impuesta y regulada legal o reglamentariamente, y todo esto con las penas más altas de la ley, simplemente no resulta plausible.

Nótese que aquí no se está poniendo en duda que antecedentes falsos que se hacen llegar a la Superintendencia serán un caso normal de aplicación del art. 59 letra a), pues muchas informaciones que deben ser remitidas al ente fiscalizador tienen, sin duda, el potencial para incidir en el precio de los valores. Más aún, es posible que éstos sean los casos más habituales, lo que justifica que la ley mencione expresa y destacadamente a la Superintendencia como destinataria relevante de los antecedentes. Lo único que aquí se niega es que esto rija respecto de cualquier información remitida a dicha autoridad fiscalizadora, aunque carezca de toda posible incidencia en el precio de los valores que se transan en el mercado.

Contra todo lo que se ha expuesto precedentemente sólo parece posible hacer valer, todavía, dos argumentos extremos que, al margen de su escasa plausibilidad, conviene abordar para efectos de exhaustividad.

Por una parte, se podría argüir que está vedado al intérprete restringir el ámbito de aplicación del art. 59 letra a) sobre la base de distinciones que la ley sencillamente no hace. Por la otra, que el art. 59 letra a) estaría llamado a cumplir una doble función en el diseño legal: por un lado sería un tipo de manipulación informativa (a secas, en sentido amplio o en la antesala de tales manipulaciones), como se ha venido sosteniendo aquí, pero también y en la misma medida, sería un tipo para la protección de las facultades fiscalizadoras de la Superintendencia, funciones que no serían contradictorias entre sí, en tanto que el legislador sería libre para formular los tipos penales del modo que mejor le parezca, incluso cobijando dos tipos tan distintos en un solo precepto.

Sobre lo primero, la ausencia de exigencias explícitas del legislador respecto del objeto de los antecedentes relevantes no constituye argumento suficiente, pues la única verdad que encierra el brocardo invocado es que cuando el legislador no distingue no cabe en principio distinguir, a menos, claro está, que haya razones para hacerlo, y en este contexto las razones sistemáticas son relativamente evidentes. Sólo una "visión de túnel", ciega al contexto y al sistema de la ley, puede llevar a contentarse con la simple ausencia de precisiones legislativas para dar por buena una 
interpretación que no distingue según la relevancia de los antecedentes en cuestión. Una mirada sistemática y que se toma en serio la gravedad de las sanciones previstas en el art. 59 letra a) no puede, en cambio, arribar a conclusiones tan toscas.

Respecto de lo segundo, un tipo penal bifronte como el propuesto no parece condecirse con la posición prominente ni con la penalidad del precepto, tanto desde la perspectiva del régimen penal del mercado de valores como de las regulaciones generales en materia de falsedades ante la autoridad, en particular en materia de falsedades ante la propia Superintendencia (art. 26 inciso tercero del DL No 3.538). Pero, adicionalmente, se opone a esa concepción un vistazo rápido al derecho penal comparado en materia de mercado de valores, que se caracteriza por una clara delimitación entre falsedades concernientes a factores relevantes para la cotización de valores en el mercado y aquéllas que simplemente perturban las facultades de fiscalización de la autoridad competente. Más aún, el repaso del derecho comparado muestra, al menos tendencialmente, que en general se prevén sanciones de menor entidad para las falsedades ante la autoridad en cuanto tales, es decir, al margen de su potencial de incidencia en el precio de los valores.

\section{RELATIVA CONVERGENCIA CON EL DERECHO COMPARADO}

Una revisión del derecho penal comparado en materia de mercado de valores muestra, en relación con el objeto de este trabajo, fundamentalmente dos cosas:

La primera, y más importante, es que se distingue con absoluta claridad la tipificación, con diversas variantes, de la entrega de antecedentes falsos con potencial incidencia en el precio de los valores, como forma de manipulación informativa, de la tipificación de la entrega falsa de antecedentes falsos a la autoridad en cuanto tal, junto a otras formas de afectar la actividad fiscalizadora de la autoridad. Y esto, hasta donde se alcanza a ver en una revista relativamente apretada, sin excepciones, es decir, no parece haber legislaciones donde se mezclen ambas cuestiones.

La segunda, si bien en esto se aprecia menos coincidencia, es que existe una clara tendencia hacia la diferenciación de sanciones, reservándose las sanciones más severas para las conductas con un potencial directo de afectación del mercado por sobre la protección sólo mediata del mismo a través de la protección de la fiscalización ${ }^{38}$.

${ }^{38}$ Una tercera sería que el tipo penal chileno del art. 59 letra a), aun entendido, como se defiende aquí, como un tipo de manipulación informativa, es un tipo es- 
Así, por ejemplo, en la legislación modélica en la materia, la SEA 1934 de los Estados Unidos, los supuestos de manipulación informativa de la Sección 9(a), que inequívocamente requieren que la información sea relevante para los precios en el mercado no se mezcla con normas sobre falsedad ante las autoridades, las que, como se sabe, son abundantes en el derecho estadounidense ${ }^{39}$.

Por su parte, en el derecho alemán, se distingue claramente entre manipulaciones informativas (sean éstas infracciones administrativas o delitos), que supone la entrega de información falsa con potencial para incidir (o que inciden efectivamente) en el precio de los valores ${ }^{40}$ y la entrega (dolosa o negligente) de informaciones incorrectas o incompletas (así como la omisión de las mismas cuando era obligatorio hacerlas) que, con independencia de su potencial de incidencia en el precio de los valores, se le deben a la autoridad ${ }^{41}$.

En el derecho suizo también se encuentran completamente separadas ambas cuestiones: el Art. 155 I letra a) de la Ley sobre infraestructuras del mercado financiero y el comportamiento de mercado en el comercio de

pecialmente amplio y eficaz, que no teme prescindir del resultado (a diferencia del tipo penal alemán) ni de exigencias subjetivas más allá del conocimiento de la (aquí postulada) idoneidad para incidir en el precio de valores (a diferencia de las tipificaciones suiza y española con su exigencia de ánimo de lucro) ni de extravagantes consideraciones patrimonialistas (a diferencia del derecho español, cuyo art. 284.2 $\mathrm{CP}$ exige enriquecimiento o perjuicio efectivo).

39 Véase sobre estas últimas, distinguiendo entre declaraciones falsas ante la administración (false statements), perjurio y declaraciones falsas ante los tribunales (perjury and false declarations) y obstrucción a la justicia (obstruction of justice) PODGOR, Ellen S. - Israel, Jerold H., White Collar Crime in a nutshell (4º edición, St. Paul, West, 2009), pp. 145 ss.; Strader, J. Kelly, Understanding White Collar Crime (3ํ. edición, New Providence - San Francisco, LexisNexis, 2011), pp. 205 ss. Es llamativo también que en las presentaciones de las facultades fiscalizadoras de la SEC y de los mecanismos para ejercerlas coercitivamente no se haga ninguna referencia a los delitos de manipulación de mercado. Cfr. Loss - Seligman - PARedes, Fundamentals of Securities Regulation, cit. (n. 19) II, pp. 1928 ss., especialmente pp. 1957 ss.

${ }^{40}$ Como ya se vio, en el $\$ 39$ II Nr. 3 WpHG (infracción administrativa) y en el $\$ 38$ I WpHG (delito).

${ }^{41}$ Recogidas en la actualidad especialmente (pero no sólo) en el $₫ 39$ II Nr. 2 WpHG como infracción administrativa (no hay delitos de entrega de información falsa aparte de los casos de manipulación informativa). Un panorama del muy complicado sistema de infracciones administrativas "informativas" pero no constitutivas de manipulación puede verse en Süssmann, Rainer en PARK, Tido (editor), Kapitalmarkt-Strafrecht. Handkommentar (Baden-Baden, Nomos, 2004), Ordnungswidrigkeiten $\$ 39$ II Nr. 1b, 2a, 3, IV WpHG (p. 658 ss.), Ordnungswidrigkeiten $\$ 39$ II Nr. 1c, 2b, IV WpHG (p. 665 ss.), Ordnungswidrigkeiten $\$ 39$ II Nr. 4, IV WpHG (p. 671 s.) y Ordnungswidrigkeiten $\$ 39$ II Nr. 1d, 2c, IV WpHG (p. 672 ss.). 
efectos y derivados (Finanzmarktinfrastrukturgesetz - FinfraG) ${ }^{42}$ se hace cargo de la difusión de información falsa o inductiva a error hecha con el propósito de alterar significativamente el precio de un efecto, y esto para obtener un beneficio económico para sí o para un tercero, previéndose una pena mayor si efectivamente se consigue un beneficio por sobre un millón de francos suizos (Art. 155 II), mientras que es una ley diferente, la Ley de Vigilancia del Mercado Financiero (Finanzmarktaufsichtsgesetz, FINMAG), la que, como su propio nombre sugiere, se hace cargo de los atentados contra las funciones fiscalizadoras de la autoridad, donde destaca, junto el tipo general del Art. 48, reprimido sólo con multa, el tipo de presentación de antecedentes falsos del Art. 45, que, debe notarse, a diferencia de la que se observa como tendencia en otros ordenamientos jurídicos, prevé la misma pena que la manipulación informativa simple, esto es, sin obtención de beneficios (privación de libertad de hasta tres años o multa ${ }^{43}$.

En el derecho español, el art. 282 bis CP, introducido mediante la Ley Orgánica 5/2010, de 22 de junio, se hace cargo de los que falsearen las informaciones que la sociedad debe publicar y difundir conforme a la legislación del mercado de valores sobre sus recursos, actividades y negocios presentes y futuros, "con el propósito de captar inversores o depositantes, colocar cualquier tipo de activo financiero, u obtener financiación por cualquier medio", con pena privativa de libertad de uno a cuatro años (o de hasta seis años y multa en caso de haberse obtenido la inversión, el depósito, la colocación del activo o la financiación, con perjuicio para el inversor, depositante, adquiriente de los activos financieros o acreedor), a lo que debe agregarse lo dispuesto en el art. 284.2 CP, referido a los que "(d)ifundieren noticias o rumores, por sí o a través de un medio de comunicación, sobre personas o empresas en que a sabiendas se ofrecieren datos económicos total o parcialmente falsos con el fin de alterar o preservar el precio de cotización de un valor o instrumento financiero, obteniendo para sí o para tercero un beneficio económico superior a los 300.000 euros o

${ }^{42}$ Desde el 1 de enero de 2016. Hasta ese momento el precepto estaba contenido, con una mínima diferencia formal, en el art. 40 a I letra a) de la Ley de Bolsas (Börsengesetz - BEHG).

43 Un panorama sobre el derecho penal suizo en la materia puede verse en WoHlers, Wolfgang, Finanz- und Kapitalmarktstrafrecht, en ACKERMANn, Jürg-Beat - Heine, Günter (editores), Wirtschaftsstrafrecht der Schweiz (Bern, Stämpfli, 2013), $\$ 14 \mathrm{n}^{\circ}$ marg. 70 ss., 92 ss. La entrada en vigor de la FinfraG en 2016 sólo tiene consecuencias formales, no de fondo en lo que respecta a las materias que interesan a este trabajo. 
causando un perjuicio de idéntica cantidad" 44 , para quienes se prevé una pena de prisión de seis meses a dos años o multa de doce a veinticuatro meses $^{45}$. En lo que concierne ahora a la afectación de las facultades de fiscalización de las autoridades competentes, ésta se recoge en un artículo separado, el art. $294 \mathrm{CP}$, que se hace cargo de los especialmente obligados que "negaren o impidieren la actuación de las personas, órganos o entidades inspectoras o supervisoras", única hipótesis en la que podría incardinarse la presentación en cuanto tal de antecedentes falsos a la autoridad ${ }^{46}$, y en todo caso con una pena mucho menor, al menos respecto de la del art. 282 bis CP, aunque mayor que la del art. 284.2: pena privativa de libertad de seis meses a tres años o multa ${ }^{47}$.

Por último, en el derecho italiano, el art. 185 del Texto Único de las disposiciones en materia de intermediación financiera (TUF, Decreto Legislativo de 24 de febrero de 1998, N 58), reprime con reclusión de uno a seis años la manipulación de mercado, también la manipulación informativa (difusión de noticias falsas) en cuanto medios "concretamente idóneos para provocar una alteración sensible del precio de instrumentos

44 Así como la muy curiosa mezcla entre la lógica del abuso de información privilegiada (que básicamente está recogida en el art. 285 del mismo Código) y la de la manipulación de mercado que representa el art. $284.3 \mathrm{CP}$, referido a los que "( $\mathrm{u}$ ) tilizando información privilegiada, realizaren transacciones o dieren órdenes de operación susceptibles de proporcionar indicios engañosos sobre la oferta, la demanda o el precio de valores o instrumentos financieros, o se aseguraren utilizando la misma información, por sí o en concierto con otros, una posición dominante en el mercado de dichos valores o instrumentos con la finalidad de fijar sus precios en niveles anormales o artificiales".

${ }^{45}$ Como se puede ver, la relación entre los arts. 282 bis y 284.2 del CP español sería, en lo grueso, similar a la que se ha postulado aquí que existe entre los arts. 59 letra a) y 61 en el derecho chileno.

46 Pone en duda la tipicidad del supuesto bajo el art. 294 CP, Martínez Ruiz, Jesús, La tutela jurídico-penal de las potestades administrativas de supervisión e inspección de los mercados financieros (Madrid - Barcelona, Marcial Pons, 2001), pp. 345 ss.

47 Hasta donde se ve, la entrada en vigor del Reglamento (UE) N ${ }^{\circ}$ 596/2014 no ha tenido todavía consecuencias legislativas en el derecho español. En particular, no tuvo incidencia en la profunda reforma al Código punitivo de ese país debida a la LO 1/2015, de 30 de marzo. Sobre la necesidad de adaptación legislativa en materia penal, Gómez Benítez, José Manuel, Aspectos penales fundamentales de la reciente Directiva y del Reglamento sobre abuso de mercado, en Análisis GA \& P (Junio 2014), disponible en:

http://www.gomezacebo-pombo.com/media/k2/attachments/aspectos-penalesfundamentales-de-la-reciente-directiva-y-del-reglamento-sobre-abuso-de-mercado. pdf 
financieros" ${ }^{\prime 4}$, sin mezclarlo en absoluto con aquellas normas relativas a la protección de la fiscalización, que obedecen a una lógica totalmente distinta, en su momento domiciliadas en los arts. 171 (tutela de la actividad de vigilancia) y 174 (comunicaciones falsas y obstaculización de las funciones de la CONSOB), y desde el año 2002 en el art. 2638 del Código Civil (obstaculización del ejercicio de las funciones de la autoridad pública de vigilancia), con una pena menor: privación de libertad de hasta un año, o de hasta cuatro años sólo si se ha ocasionado perjuicio patrimonial.

Obviamente no se sigue de esta brevísima revisión del derecho comparado que en supuestos concretos no sea perfectamente posible que el tipo de lo que aquí se ha llamado simple "obstrucción de la fiscalización" pueda satisfacer al mismo tiempo las exigencias de un tipo de manipulación informativa, caso en el cual debería poder afirmarse un concurso ideal de delitos ${ }^{49}$. Pero lo que sí se desprende de esta revisión es que ambas figuras delictivas son cosas completamente diferentes que el derecho penal comparado ve, al parecer de modo invariable, también como cosas diferentes, lo que, en conjunto con las razones valorativas que se han hecho valer en los apartados precedentes de este trabajo, hacen que sea muy poco plausible la pretensión de que en el art. 59 letra a) pueda cobijarse, además de la manipulación informativa, la entrega de antecedentes falsos que en sí mismos no tienen incidencia en el precio de los valores que se transan en el mercado, por el solo hecho de que fueron hechos llegar a la Superintendencia.

Menos aún si se tiene en cuenta la polémica existente en torno a la legitimidad de una protección jurídico-penal de la fiscalización administrativa, contra la que un sector relevante de la literatura opone que estaría tan lejana de los bienes que en último término se quiere proteger, que ya no podría reconstruirse conceptualmente como genuina protección de dichos bienes ${ }^{50}$. Cabe aclarar que aquí no se suscriben esas objeciones y que, más bien al contrario, se afirma la legitimidad y conveniencia intrínsecas de una protección jurídico-penal específica de la fiscalización en cuanto tal en mercados regulados. Pero la cuestión es si puede afirmarse que en

48 Sobre las manipulaciones informativas en el derecho italiano, AmATI, Enrico, Abusi di mercato e sistema penale (Torino, Giappichelli, 2012), pp. 182 ss.

49 Pues no parece que los tipos en disputa protejan lo mismo como para poder aceptar un concurso aparente de leyes.

${ }^{50}$ Crítico sobre esto Silva SÁnCHEZ, Jesús María: Hacia el derecho penal del "Estado de la prevención”, en Silva SÁnchez, Jesús María (director), ¿Libertad económica o fraudes punibles? (Madrid - Barcelona, Marcial Pons, 2003), pp. 307 ss.; véase también Alessandri, Alberto, Parte generale, en Pedrazzi, Cesare et al, Manuale di diritto penale dell'impresa ( $2^{\circ}$ edición, Bologna, Monduzzi, 2000), pp. 31 ss. 
el derecho vigente en Chile esa función pueda ser atribuida al art. 59 a), y tanto el contexto como, sobre todo, la penalidad prevista para este precepto conducen a la respuesta negativa. Como se ha dicho en el apartado precedente: la protección penal de la fiscalización de la Superintendencia en cuanto tal es un asunto que se regula en otro lugar.

\section{CONCLUSIÓN}

Con base en todo lo precedentemente expuesto, se puede concluir que no es típica a los efectos del art. 59 letra a) la entrega de informaciones falsas que no versan sobre factores que puedan incidir en el precio de los valores que se transan en el mercado. Esto porque el art. 59 letra a) contiene un tipo de (al menos potencial) manipulación de precios o de mercado, concretamente el tipo genérico de manipulación informativa, única lectura que se aviene con la posición prominente y, sobre todo, con la penalidad prevista por el precepto.

Por el contrario, no se aviene con esa posición y penalidad una inteligencia del precepto que lo degrade a la categoría de mero delito de "obstrucción a la fiscalización", esto es, de presentación de antecedes falsos, punible en cuanto tal, con independencia de los efectos potenciales de la información en cuestión. Semejante lectura implicaría aceptar una importante distorsión valorativa en relación con el régimen general de falsedades ante la autoridad en el derecho chileno, y en particular con el tratamiento de las declaraciones falsas ante la propia Superintendencia, conforme al art. 26 inciso tercero de su Ley Orgánica.

Por último, implicaría atribuirle al derecho chileno vigente en la materia la rareza de regular promiscuamente cuestiones que en general en el derecho comparado se abordan por separado y, las más de las veces, con penas diferentes, habitualmente más altas tratándose de informaciones que, más que relevantes para la fiscalización, son relevantes para los intereses de fondo a los que dicha fiscalización se debe.

\section{BibLIOGRAFÍA}

Alessandri, Alberto, Parte generale, en Pedrazzi, Cesare et al, Manuale di diritto penale dellimpresa ( $2^{\circ}$ edición, Bologna, Monduzzi, 2000)

Allen, Franklin - Gale, Douglas, Stock-price Manipulation, en The Review of Financial Studies 5 (1992) 3

Aматі, Enrico, Abusi di mercato e sistema penale (Torino, Giappichelli, 2012)

Cury, Enrique, El Decreto Ley No 280, sobre delito económico, en Revista Chilena de Derecho 1 (1974)

GarCía, Gonzalo, Equivalentes funcionales en los delitos económicos. Una aproximación de solución ante la falta de lesividad material en delitos de presentación de información falsa al mercado de valores, en Politica Criminal 23 (2017) 
Garrido, Mario, Derecho penal (Santiago, Editorial Jurídica de Chile, 2000) IV

Gómez Benítez, José Manuel, Aspectos penales fundamentales de la reciente Directiva $y$ del Reglamento sobre abuso de mercado, en Análisis GA \&P (Junio 2014), disponible en:

http://www.gomezacebo-pombo.com/media/k2/attachments/aspectos-penales-fundamentales-de-la-reciente-directiva-y-del-reglamento-sobre-abuso-de-mercado.pdf

Gómez Martín, Víctor, Los delitos especiales (Madrid, Edisofer, 2006)

Llanos, Hugo, El Decreto Ley No 280, sobre delito económico, en Revista Chilena de Derecho 1 (1974)

LoNDOÑo, Fernando, Ilícito de manipulación bursátil: fenómeno y lesividad. Aspectos de politica sancionatoria, en Politica Criminal 15 (2013)

Londoño, Fernando, Aproximación histórico-comparada al Título VIII de la Ley de Mercado de Valores: bases para el reconocimiento de un contenido anti-manipulativo, en Politica Criminal 20 (2015)

Loss, Louis - Seligman, Joel - Paredes, Troy, Fundamentals of Securities Regulation ( $6^{\circ}$ edición, New York, Wolters Kluwer, 2011)

Martínez Ruiz, Jesús, La tutela jurídico-penal de las potestades administrativas de supervisión e inspección de los mercados financieros, (Madrid - Barcelona, Marcial Pons, 2001)

Moloney, Niamh, EU Securities and Financial Markets Regulation ( $3^{\circ}$ edición, New York, Oxford University Press, 2014)

Moreira, Alejandro, Comentario a sentencias dictadas en caso ALFA por delitos concursales, infracción al mercado de valores y obtención fraudulenta de crédito, en Revista Jurídica del Ministerio Público 59 (2014)

Podgor, Ellen S. - Israel, Jerold H., White Collar Crime in a nutshell (4º edición, St. Paul, West, 2009)

Robles Planas, Ricardo, La participación en el delito: fundamento y límites (Madrid Barcelona, Marcial Pons, 2003)

Robles Planas, Ricardo, Garantes y cómplices (Barcelona, Atelier, 2007)

Siems, Mathias - Nelemans, Matthijs, The Reform of the EU Market Abuse Law: Revolution or Evolution?, en Maastricht Journal of European and Comparative Law 19 (2012)

Silva Sánchez, Jesús, Hacia el derecho penal del "Estado de la prevención”, en Silva SÁnCHEZ, Jesús (director), ¿Libertad económica o fraudes punibles? (Madrid Barcelona, Marcial Pons, 2003)

Sorgenfrei, Ulrich en PARK, Tido (editor), Kapitalmarkt-Strafrecht. Handkommentar (Baden-Baden, Nomos, 2004)

Strader, J. Kelly, Understanding White Collar Crime ( $3^{\circ}$ edición, New Providence San Francisco, LexisNexis, 2011)

Süssmann, Rainer en Park, Tido (editor), Kapitalmarkt-Strafrecht. Handkommentar (Baden-Baden, Nomos, 2004)

Tiedemann, Klaus, Manual de Derecho penal económico. Parte especial (varios traductores, Lima, Grijley, 2012)

Torres, Angélica, El delito de entrega de información falsa al mercado como delito base o precedente de lavado de dinero, en Revista Jurídica del Ministerio Público 64 (2015)

WoHLERs, Wolfgang, Finanz- und Kapitalmarktstrafrecht, en ACKERMANN, Jürg-Beat HeINE, Günter (editores), Wirtschaftsstrafrecht der Schweiz (Bern, Stämpfli, 2013) 